\title{
Do Diabetic Veterans Use the Internet? Self-Reported Usage, Skills, and Interest in Using My HealtheVet Web Portal
}

Alex H. Cho, M.D., M.B.A., ${ }^{1}$ Nedal H. Arar, M.A., M.S., Ph.D., ${ }^{2}$ David E. Edelman, M.D., MHSc, ${ }^{1,3}$ Patricia H. Hartwell, M.A.T., ${ }^{3}$ Eugene Z. Oddone, M.D., MHSc, ${ }^{1,3}$ and William S. Yancy, Jr., M.D., MHSc ${ }^{1,3}$

\section{${ }^{1}$ Division of General Internal Medicine, Duke University, Durham, North Carolina. \\ ${ }^{2}$ Veterans Evidence-Based Research Dissemination and Implementation Center, South Texas Veterans Health Care System, San Antonio, Texas. \\ ${ }^{3}$ Center for Health Services Research in Primary Care, Durham VA Medical Center, Durham, North Carolina.}

This work was performed at the Center for Health Services Research in Primary Care at the Durham VA Medical Center.

\section{Abstract}

Objective: The Veterans Health Administration has developed My HealtheVet (MHV), a Web-based portal that links veterans to their care in the veteran affairs (VA) system. The objective of this study was to measure diabetic veterans' access to and use of the Internet, and their interest in using MHV to help manage their diabetes. Materials and Methods: Cross-sectional mailed survey of $201 \mathrm{pa-}$ tients with type 2 diabetes and hemoglobin $A_{1 \mathrm{c}}>8.0 \%$ receiving primary care at any of five primary care clinic sites affiliated with a VA tertiary care facility. Main measures included Internet usage, access, and attitudes; computer skills; interest in using the Internet; awareness of and attitudes toward MHV; demographics; and socioeconomic status. Results: A majority of respondents reported having access to the Internet at home. Nearly half of all respondents had searched online for information about diabetes, including some who did not have home Internet access. More than a third obtained "some" or "a lot" of their health-related information online. Forty- one percent reported being "very interested" in using MHV to help track their home blood glucose readings, a third of whom did not have home Internet access. Factors associated with being "very interested" were as follows: having access to the Internet at home $(\mathrm{p}<0.001)$, " lot/some" trust in the Internet as a source of health information $(\mathrm{p}=0.002)$, lower age $(\mathrm{p}=0.03)$, and some college $(\mathrm{p}=0.04)$. Neither race $(\mathrm{p}=0.44)$ nor income $(\mathrm{p}=0.25)$ was significantly associated with interest in MHV. Conclusions: This study found that a diverse sample of older VA patients with sub-optimally controlled diabetes had a level of familiarity with and access to the Internet comparable to an age-matched national sample. In addition, there was a high degree of interest in using the Internet to help manage their diabetes.

Key words: veterans, medical informatics, patient preferences, diabetes, self-care, Internet

\section{Introduction}

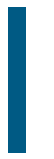
n 2003, the Veterans Health Administration of the Department for Veteran Affairs (VA) launched its own Internet venture directed at veterans and their families, called My HealtheVet (MHV). ${ }^{1}$ A screenshot is shown in Figure 1. MHV provides access to the following resources: evidence-based health information; health logs that allow veterans to record medications and other selfentered health data, such as blood glucose and blood pressure readings; online prescription drug refill; access to providers' notes; patient-directed reminders for preventive health services; and secure messaging with participating VA providers. ${ }^{2,3}$ MHV thus gives veterans a wide array of tools that can potentially help them collaborate with their healthcare providers in monitoring the status of their chronic illnesses, and has been cited as a possible model for other online personal health records. ${ }^{4}$ 


\section{CHO ET AL.}

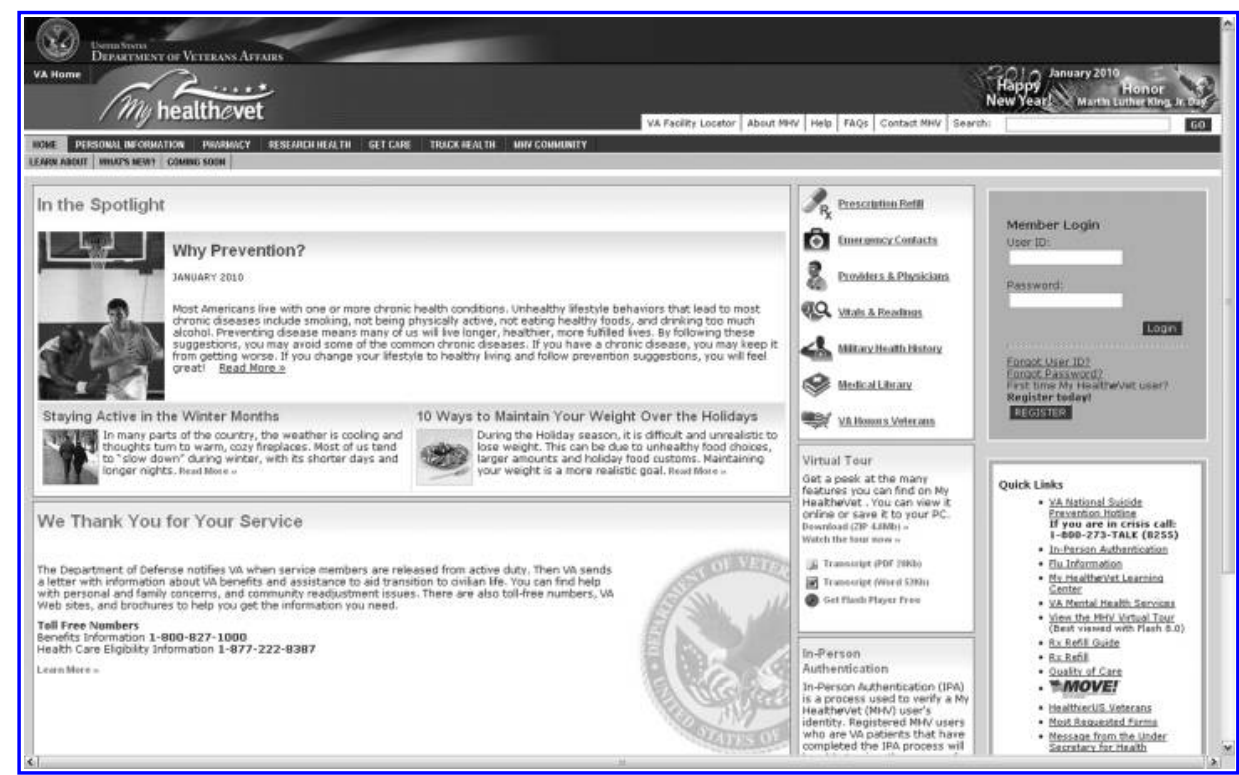

Fig. 1. Screenshot of My HealtheVet, the veteran affairs's Web-based healthcare portal.

tions: Are veterans with chronic illnesses interested in using the Internet for health-related purposes? Do they have access to computers with Internet connections? Are they (or their caregivers) computer-literate enough to use these tools?

\section{Materials and Methods PARTICIPANTS}

This study was conducted at the VA Medical Center (VAMC) in Durham, North Carolina. Using the VA electronic health record, computerized patient record systemVistA, which is publicly available software on which computerized patient record system runs-we identified veterans receiving primary care at one of five Durham VAMC-affiliated outpatient clinics with documented diabetes mellitus and last hemoglobin $\mathrm{A}_{1 \mathrm{c}}$ (Hgb A1c) > 8.0\%. Hgb A1c reflects blood glucose control over the past 2-3 months; the American Diabetic

Issues of major concern, however, include veterans' access to the Internet, particularly older veterans, as well as their inclination and ability to use the Internet for health-related purposes. For example, veterans who use VA healthcare services tend to be older, more likely to be retired or unemployed, and more likely to be uninsured compared with veterans who do not use VA healthcare. ${ }^{5}$ People with the aforementioned characteristics are also less likely to be familiar with computers and the Internet. ${ }^{6}$ These disparities also exist among patients with chronic illness, as well as members of minority groups. ${ }^{7,8}$ These findings do not signal a lack of interest; multiple surveys have found great interest among minorities and older individuals in using computers and the Internet in their healthcare. ${ }^{5,9}$ Similar surveys have not been done among veterans.

Both within and beyond the VA, glycemic control continues to be suboptimal.

Preliminary randomized, controlled trial evidence suggests that Internet-based portals allowing communication of self-monitoring results and management recommendations between patients and providers can improve diabetes outcomes, even after more than 2 years of use. ${ }^{10-13}$ Potential interest and acceptance of such an intervention is unknown.

To gauge the potential for MHV to meaningfully support veterans' management of chronic illness, we wanted to ask the following ques-
Association recommends a goal of $7.0 \%$ or lower for people with diabetes. We therefore deliberately selected for veterans with out-of-control diabetes, to survey a representative, chronically ill population.

Additional eligibility criteria included the following: correct contact information, ability to complete the survey without assistance from study staff, no comorbid psychotic mental illness, and not participating in another ongoing study. Entry into a drawing for three $\$ 50$ prizes was offered as an incentive for completing the survey. The study was approved by the Institutional Review Board at the Durham VAMC.

Surveys were mailed to all eligible subjects, and followed up by phone calls to verify receipt. If after three phone attempts (including at least one after business hours) the patient was still not reached, the patient was classified as "no response."

\section{DEMOGRAPHICS}

Demographic, socioeconomic, health, and Internet-related characteristics are summarized in Table 1. Mean age was 58.9 years, and 97\% were men. African Americans comprised 35\% of the sample; $60 \%$ were white. Over one-third (37\%) did not have formal education beyond high school, and 59\% reported annual household income $\leq \$ 30,000$. Mean Hgb A1c was 9.6\%. 


\section{DO DIABETIC VETERANS USE THE INTERNET?}

Table 1. Demographics, Hemoglobin $A_{1 c}$ Internet Usage and Attitudes of Study Participants

OVERALL $(N=201)^{a}$

\begin{tabular}{|c|c|}
\hline Mean age, years & $58.9(10.4)^{b}$ \\
\hline Men, $n(\%)$ & 194 (97) \\
\hline \multicolumn{2}{|l|}{ Race/ethnicity, $n(\%)$} \\
\hline African American & $70(35)$ \\
\hline White & $120(60)$ \\
\hline Other & $11(5)$ \\
\hline \multicolumn{2}{|l|}{ Income, $n(\%)$} \\
\hline$\leq \$ 30,000$ per year & $91(59)$ \\
\hline$>\$ 30,000$ per year & $64(41)$ \\
\hline Did not answer & 46 \\
\hline \multicolumn{2}{|l|}{ Education, $n(\%)$} \\
\hline High school diploma or less & $71(37)$ \\
\hline Some college or more & $126(63)$ \\
\hline Did not answer & 4 \\
\hline Travel time to VA, min & $65(48)$ \\
\hline $\mathrm{Hgb} \mathrm{A} 1 \mathrm{c}, \%$ & $9.6(1.6)$ \\
\hline Track sugars at home, $n(\%)$ & $168(84)$ \\
\hline Ever been online, $n(\%)$ & $120(60)$ \\
\hline Access to Internet at home, $n(\%)$ & $119(59)$ \\
\hline \multicolumn{2}{|l|}{ Days online (in past 30 ) } \\
\hline Mean, days & $10.1(12.6)$ \\
\hline Respondents online 0 out of $30, n(\%)$ & $96(48)$ \\
\hline Respondents online 30 out of $30, n(\%)$ & $41(20)$ \\
\hline Ever looked diabetes up online, $n(\%)$ & $95(47)$ \\
\hline \multicolumn{2}{|l|}{ Trust Internet } \\
\hline A lot/some, $n(\%)$ & $122(61)$ \\
\hline Interested in e-mailing providers Very, $n(\%)$ & $80(40)$ \\
\hline Interested in MHV to manage diabetes Very, $n(\%)$ & $82(41)$ \\
\hline
\end{tabular}

${ }^{a}$ Not all respondents answered all questions.

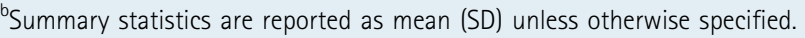

Hgb A1c, hemoglobin $A_{1 c}$; VA, veteran affairs; MHV, My HealtheVet.

\section{SURVEY}

The Veterans' Internet Survey of Use, Access, and Leanings asked about the following issues regarding the Internet: access ("Do you have access to the Internet from a home computer?"), use ("In the past 30 days, how many days did you go online to use the Internet or e-mail?"), and attitudes ("How much do you trust the Internet to provide accurate information about health problems or health issues?") Possible responses were "Not at all," "Not too much," "Somewhat," and "A lot." The survey was modeled (with permission) after the Kaiser Family Foundation's recent national survey of older adults and their use of the Internet for health-related purposes. ${ }^{6}$

A computer skills section asked about overall comfort using computers and the Internet as well as comfort performing specific tasks such as checking and sending e-mail. Responses were Likertscaled from 1 to 5 , with 1 being "not at all" comfortable and 5 being "very" comfortable.

Additional questions were specific to MHV, asking about veterans' awareness and current use of the Web portal (if any), as well as their interest in learning to use it to help manage diabetes ("How interested would you be in learning how to use a Web site like My HealtheVet to track your blood sugars and how to send the record to a healthcare provider?"). Possible responses were "Not at all interested," "A little interested," "Somewhat interested," and "Very interested." A screenshot and one-paragraph description of MHV accompanied these MHV-related questions.

\section{STATISTICAL ANALYSIS}

Summary statistics were generated for responses to all survey questions. Differences between respondents with Internet access at home and those without were assessed using $t$-tests and $\chi^{2}$-tests. Bivariate analyses of factors associated with interest in using MHV to help manage one's diabetes were performed, with interest dichotomized as "Very interested" versus other responses, using both simple logistic regression and $\chi^{2}$-tests. Backward selection was used to build a multivariable logistic regression model predicting interest in using MHV in this manner. SAS Enterprise Guide 3.0 (Cary, NC) and Microsoft Excel 2003 (Microsoft, Redmond, WA) were used for all analyses.

\section{Results}

Initially, 421 potentially eligible VA patients were identified. Of these, 44 were deemed ineligible for the study: 6 were deceased, 17 self-reported (or their caregivers reported) being unable to complete the survey due to disability or acute illness, 2 had psychotic mental illness, and 19 had incorrect contact information. Of the 377 eligible veterans finally identified, 201 completed surveys for a response rate of 53\%. This progression is illustrated in Figure 2. 


\section{CHO ET AL.}

\section{ACCESS TO AND USAGE OF THE INTERNET}

A majority of respondents-119 (59\%)-reported having access to the Internet at home (Table 1). Nearly half of all respondents-95 (47\%)-had searched online for information about diabetes, 17 of whom did not have home Internet access. Seventy-eight (39\%) obtained "some" or "a lot" of their health-related information online.

Statistically significant differences between respondents having home Internet access and those without included income, education, ever having been online, days online, ever searched for diabetes information online, trust in the Internet as a source for health-related information, interest in e-mailing VA providers (all with $p<0.001$ ), age ( $p=0.005$ ), and interest in learning to use MHV to track home blood glucose readings ( $p=0.04$ ) (Table 2).

In terms of Internet usage, $41(20 \%)$ reported going online everyday in the past 30 days, whereas 96 (48\%) did not go online at all, including 25 (12\%) with Internet access at home. The mean number of days online was $16.5 \pm 12.5$ days; the median was 20 . Of those who did not have home Internet access, 10 (5\%) reported having gone online at least once in the past 30 days.
Twenty-nine (14\%) said that they could go online at a family member's home, and 39 (19\%) said that they could go online at an alternate location, such as a friend's home, library, or other outside location. Only 14 (7\%) reported having absolutely no access to the Internet at all. A majority-111 (55\%)-also reported knowing someone they trusted who likely or very likely could help them go online as regularly as once or twice a week, including 19 (9\%) of those without Internet access at home.

\section{COMFORT WITH INTERNET}

In general, respondents reported being moderately comfortable with a range of computer- and Internet-related tasks (Table 3). Equal numbers of respondents reported being "very" comfortable with using the Internet overall as reported being "not at all" comfortable (63 and 66; 31\% and 33\%, respectively). However, more respondents reported being "not at all" comfortable than "very" comfortable finding information online, using e-mail, and downloading files. Of note, 59 (29\%) also reported being "not at all" comfortable with turning a computer on and getting started.

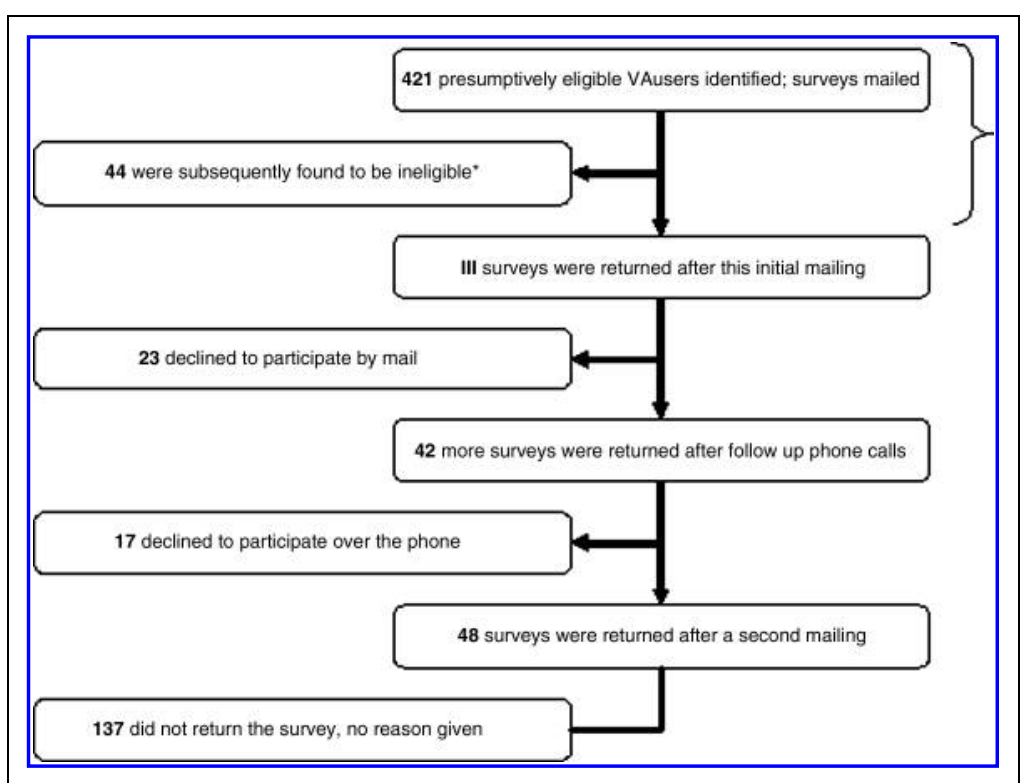

Fig. 2. Flowchart showing the outcomes of efforts to survey this sample of veteran affairs (VA) users with suboptimally controlled diabetes. Of the 44 found to be ineligible, 6 were deceased; 17 were unable to complete the survey due to disability, acute illness, or inability to answer the questions asked; 2 had psychotic mental illness; and 19 had incorrect contact information.

\section{INTEREST IN USING MHV TO HELP MANAGE DIABETES}

Regarding the VA's Web portal MHV, 35 (18\%) had heard of MHV before this survey, and 17 (9\%) reported having used it. However, 82 (41\%) reported being "very interested" in using it to help track their home blood glucose readings, including 27 (34\%) who did not have home Internet access.

In bivariate analyses, factors associated with being "very interested" in learning how to use MHV to help manage their diabetes were as follows: having access to the Internet at home ( $p<0.001)$, "a lot/some" trust in the Internet as a source of health information $(p=0.002)$, lower age ( $p=0.03)$, and some college or beyond in terms of formal education $(p=0.04)$. Neither race $(p=0.44)$ nor income $(p=0.25)$ was significantly associated with interest in MHV. These results are summarized in Table 4.

A final multivariable model predicting interest in using MHV for diabetes management included age and trust in the Internet ( $p<0.001$, adjusted $r^{2}=0.094, c$ statistic $=0.63$ ). The odds of being "very interested" in learning how to use MHV to help manage one's diabetes increased by 1.4 for every decade younger a respondent was (95\% confidence interval, 1.1 to $1.9 ; p=0.01$ ), and by 2.3 for having "a lot/some" trust in the Internet (95\% confidence interval, 1.2 to $4.4 ; p=0.01$ ). 


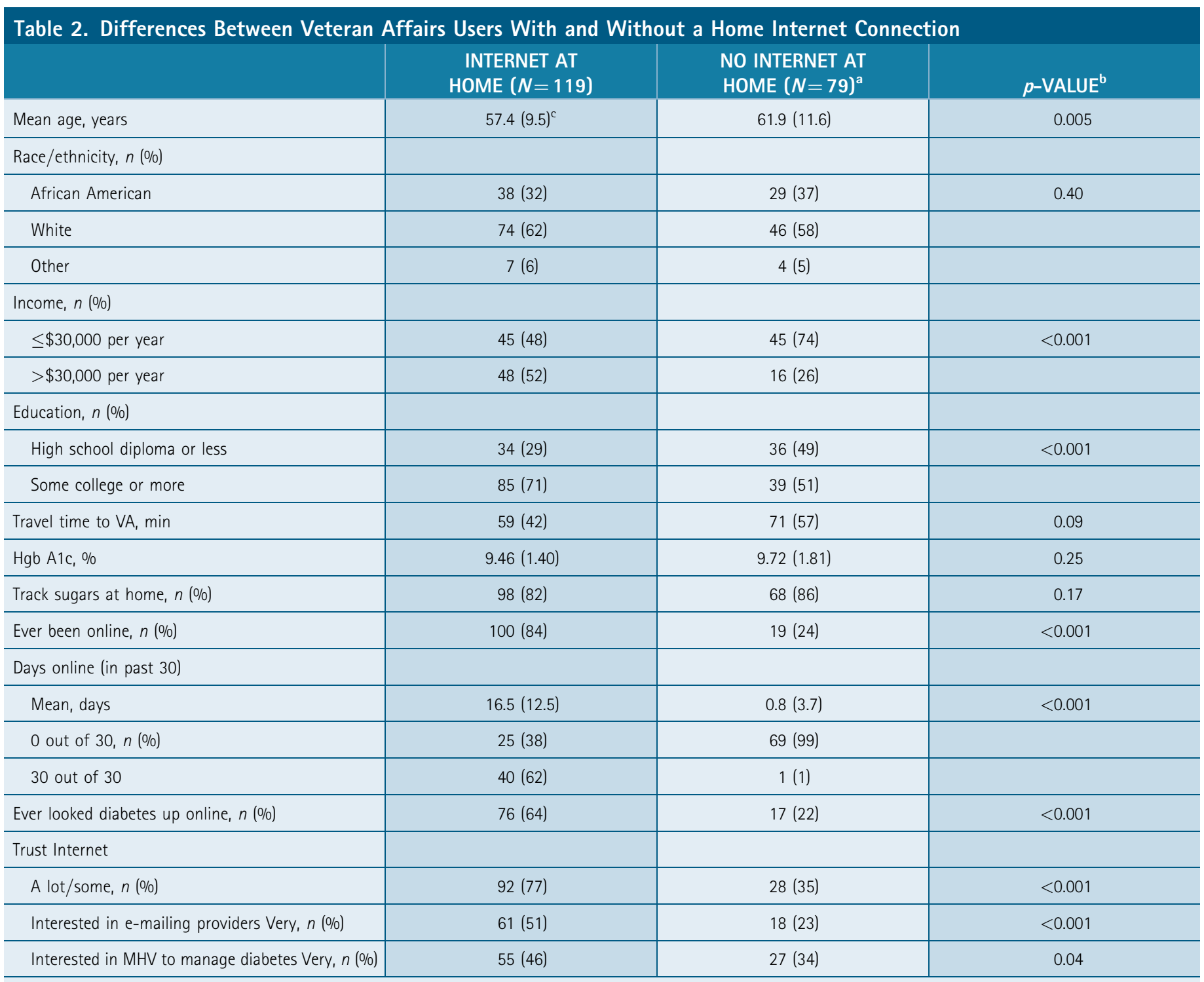

${ }^{a}$ Not all respondents answered all questions, including three who did not answer question about home Internet access.

${ }^{b} p$-Values compare these two groups by $t$-test or $\chi^{2}$-test.

'Summary statistics are reported as mean (SD) unless otherwise specified. 


\section{CHO ET AL.}

\begin{tabular}{|c|c|c|c|c|}
\hline & $\begin{array}{c}\text { AVERAGE } \\
\text { SCORE, }^{a} \text { 0-5 (SD) }\end{array}$ & $\begin{array}{l}\text { VERY COMFORTABLE/ } \\
\text { CONFIDENT, } N(\%)\end{array}$ & $\begin{array}{c}\text { NOT AT ALL } \\
\text { COMFORTABLE/ } \\
\text { CONFIDENT, } N(\%)\end{array}$ & $\begin{array}{c}\text { DID NOT } \\
\text { ANSWER, } N\end{array}$ \\
\hline Comfort using a mouse & $3.3(1.7)$ & $87(43)$ & $59(29)$ & 4 \\
\hline $\begin{array}{l}\text { Comfort turning computer } \\
\text { on/getting started }\end{array}$ & $3.2(1.7)$ & $81(40)$ & $59(29)$ & 6 \\
\hline $\begin{array}{l}\text { Overall comfort using a } \\
\text { computer }\end{array}$ & $3.1(1.7)$ & $70(35)$ & $61(30)$ & 6 \\
\hline Comfort checking e-mail & $2.9(1.8)$ & $66(33)$ & $83(41)$ & 4 \\
\hline $\begin{array}{l}\text { Overall comfort using the } \\
\text { Internet }\end{array}$ & $2.9(1.7)$ & $63(31)$ & 66 (33) & 4 \\
\hline Comfort saving/opening a file & $2.8(1.7)$ & $55(27)$ & 78 (39) & 4 \\
\hline Comfort using word processor & $2.8(1.7)$ & $54(27)$ & 75 (37) & 5 \\
\hline $\begin{array}{l}\text { Confidence in ability to find info } \\
\text { on the Web }\end{array}$ & $2.8(1.7)$ & $53(26)$ & 79 (39) & 4 \\
\hline Comfort sending e-mail & $2.7(1.8)$ & $62(31)$ & $89(44)$ & 4 \\
\hline $\begin{array}{l}\text { Confidence in ability to } \\
\text { download files }\end{array}$ & $2.6(1.7)$ & $50(25)$ & $91(45)$ & 4 \\
\hline $\begin{array}{l}\text { Confidence in ability to send } \\
\text { attachments }\end{array}$ & $2.5(1.7)$ & $49(24)$ & $95(47)$ & 4 \\
\hline $\begin{array}{l}\text { Comfort setting up new } \\
\text { computer }\end{array}$ & $2.4(1.7)$ & $45(22)$ & $99(49)$ & 4 \\
\hline $\begin{array}{l}\text { Comfort setting up new Internet } \\
\text { connection }\end{array}$ & $2.4(1.7)$ & $42(21)$ & $103(51)$ & 4 \\
\hline
\end{tabular}

${ }^{\text {a }}$ Responses were Likert-scaled ranging from 5 (very) to 0 (not at all). SD, standard deviation.

\section{Discussion}

These results suggest that a substantial number of VA users with suboptimally controlled type 2 diabetes have access to the Internet, and have gone online to search for information about diabetes. There also seems to be a high degree of interest in learning how to use the VA's MHV Web portal to help manage their diabetes. Thus, there appears to be an important opportunity to use MHV and other online tools to help deliver self-management support to patients outside of the healthcare setting. ${ }^{14,15}$

Despite the encouraging level of interest, it is also clear that MHV cannot yet be a universal solution. Significant barriers to its use continue to exist. Increased age and lower levels of education, income, and experience with and trust of the Internet all appear to be associated with lack of an Internet connection at home and lower interest in using an Internet-based tool to help improve control of their chronic illness. There are also a substantial number of VA users with very limited knowledge of how to operate computers and navigate the Internet, resulting in what appears to be a bimodal distribution of experienced, confident users and nonusers who are "not at all" comfortable with the Internet.

These findings are consistent with research on older Americans conducted by the Kaiser Family Foundation, which undertook a national survey of older U.S. adults and their use of the Internet for health-related purposes. The survey found that 70\% of adults between the ages of 50 and 64 had gone online at least once before. Two-thirds of this group reported having Internet access at home. The proportion of respondents reporting going online was lower for those 


\section{Table 4. Factors Associated with Interest in Using My HealtheVet to Help Manage One's Diabetes SIGNIFICANTLY ASSOCIATED WITH BEING VERY INTERESTED ${ }^{a}$ IN MHV?}

\begin{tabular}{l|l|c} 
& \multicolumn{1}{c}{ VERY INTERESTED ${ }^{\text {IN MHV? }}$} & \multicolumn{1}{c}{$p$-VALUE } \\
\hline Age & Yes (lower age) & 0.03 \\
\hline Race (white vs. nonwhite) & No & 0.44 \\
\hline Education (some college vs. high school only) & Yes (more schooling) & 0.04 \\
\hline Income (>\$30,000/year vs. $\leq \$ 30,000 /$ year) & No & 0.25 \\
\hline $\begin{array}{l}\text { Trust in the Internet as source of health info } \\
\text { (a lot/some vs. not too much/not at all) }\end{array}$ & Yes (greater trust) & 0.002 \\
\hline Home access to the Internet (yes vs. no) & Yes (access at home) & $<0.001$ \\
\hline
\end{tabular}

${ }^{a}$ Responses were dichotomized into very interested versus other answers.

with lower incomes, less education, and female sex, as well as older age. ${ }^{6}$

However, barriers to Internet use among veterans may decrease over time, as evidenced by the finding that younger veterans have more access to, familiarity with, and interest in using the Internet. ${ }^{16}$ Returning veterans from the wars in Iraq and Afghanistan are likely to be younger than our survey respondents and therefore more familiar with newer technologies, meaning that they may face fewer of these barriers. Interest and familiarity should also increase as costs of computers and access to the Internet continue to decline.

Several of these barriers are immediately addressable. Given the significant interest in the use of the Internet to address health issues, even from those who face these barriers, efforts should be made to enhance access to the Internet. For example, in the VA, surplus computers could be made available to veterans, and relatively inexpensive dial-up connections subsidized. On-site computer classes could give Internet-naive veterans instruction in computer and Internet fundamentals, helping to overcome basic mistrust of this technology. MHV also provides users with a single, trusted source for health information, and as MHV becomes more functional, newer features will further incentivize its use.

Strengths of this study include a good response rate, with over half of eligible veterans responding, and the clinical importance (inadequately controlled diabetes) and demographic representativeness of the surveyed population. Limitations of this study include the use of a brief paper-based description of MHV as the product concept to gauge their interest in using it; the survey's cross-sectional nature; and the fact that intention can never substitute for actual use. Response bias may also have been a problem, as veterans who were more interested in computers and the Internet may have been more likely to complete the survey. The percentage who reported actually having used MHV (9\%) in this study was slightly higher than the percentage of VA patients who are registered MHV users nationally (5\%). In addition, the surveyed veterans were almost entirely men and therefore may not represent the opinions of women veterans.

Our study found that a diverse sample of older VA patients with sub-optimally controlled diabetes had a level of familiarity with and access to the Internet comparable to an age-matched national sample. In addition, there was a high degree of interest in using the Internet to help manage their diabetes. Future research should test the usability, functionality, and efficacy of MHV in helping veterans with diabetes self-manage this chronic illness.

\section{Acknowledgment}

This work was supported by Grant 5T32HS00079 from Agency for Healthcare Research and Quality.

\section{Disclosure Statement}

No competing financial interests exist.

\section{REFERENCES}

1. Perlin JB. Veteran health care: Meeting tomorrow's challenges. VA HSR\&D Forum. 2005;June:1-2. Available at http://www.hsrd.research.va.gov/ publications/internal/forum06_05.pdf.

2. My HealtheVet History. Available at www.myhealth.va.gov/ (last accessed October 7, 2009). 


\section{CHO ET AL.}

3. Charters KG. My HealtheVet Update: Personal Health Record. Presentation to the Summer Institute in Nursing Informatics. Baltimore, MD. May 21, 2009. Available at http://www.kljcharters.com/sini2009/personalhealthrecord update.pdf.

4. VA's web-based personal health record can be a model for others. Internet Healthc Strategic 2005;7:8-10.

5. Liu C, Macijewski, ML, Sales A. Changes in characteristics of veterans using the VHA healthcare system between 1996 and 1999. Health Policy Res Syst 2005;3:5-11.

6. Rideout V, Neuman T, Kitchman M, Brodie M. e-Health and the elderly: How seniors use the Internet for health information. Report by the program for the study of entertainment media and health. Kaiser Family Foundation, Menlo Park, CA, 2005.

7. Jackson $C L$, Batts-Turner ML, Falb MD, Yeh $\mathrm{H}$, Brancati FL, Gary TL. Computer and Internet use among urban African Americans with type 2 diabetes. Health 2005;82:575-583.

8. Grant RW, Cagliero E, Chueh HC, Meigs JB. Internet use among primary care patients with Type 2 diabetes. J Gen Intern Med 2005;20:470-473.

9. Singh H, Fox SA, Petersen NJ, Shethia A, Street RL Jr. Older patients' enthusiasm to use electronic mail to communicate with their physicians: Cross-sectional survey. J Med Internet Res 2009;11:e18.

10. Kwon HS, Cho JH, Kim HS, Song BR, Ko SH, Lee JM, Kim SR, Chang SA, Kim HS, Cha BY, Lee KW, Son HY, Lee JH, Lee WC, Yoon KH. Establishment of a blood glucose monitoring system using the Internet. Diabetes Care 2004;27:478-483.

11. Cho JH, Chang SA, Kwon, HS, Choi YH, Ko SH, Moon SD, Yoo SJ, Song KH, Son HS, Kim HS, Lee WC, Cha BY, Son HY, Yoon K. Long-term effect of the Internetbased glucose monitoring system on $\mathrm{HbA1c}$ reduction and glucose stability. Diabetes Care 2006;29:2625-2631.

12. McMahon GT, Gomes HE, Hickson-Hohne S, Hu TM, Levine BA, Conlin PR. Webbased care management in patients with poorly controlled diabetes. Diabetes Care 2005;28:1624-1629.
13. Goldberg HI, Ralston JD, Hirsch IB, Hoath JI, Ahmed KI. Using an Internet comanagement module to improve the quality of chronic disease care. Jt Comm J Qual Patient Saf 2003;29:443-451.

14. Jackson GL, Weinberger M. A decade with the chronic care model: Some progress and opportunity for more. Med Care 2009;47:929-931.

15. Glasgow RE, Funnell MM, Bonomi AE, Davis C, Beckham V, Wagner EH. Selfmanagement aspects of the improving chronic illness care breakthrough series: Implementation with diabetes and heart failure teams. Ann Behav Med $2002 ; 24: 80-87$

16. Schneiderman Al, Lincoln $A E$, Curbow $B$, Kang HK. Variations in health communication needs among combat veterans. Am J Public Health 2004;94:2074-2076.

Address correspondence to:

Alex H. Cho, M.D., M.B.A.

Division of General Internal Medicine Duke University

106 Davison Building

DUMC Box 3701

Durham, NC 27710

E-mail: alex.cho@duke.edu

Received: November 13, 2009

Revised: January 29, 2010

Accepted: February 1, 2010 